\section{Dr Leila Keys}

Formerly Consultant Psychiatrist, St Bernard's Hospital, Southall, Heatherwood Hospital, Ascot, and King Edward VII Hospital, Windsor

Dr Leila Keys was born in Chennai (Madras) on 7 October 1926 and died in London on 12 September 2007. Leila obtained her MBBS from Madras in 1950 and initially practiced medicine in southern India before arriving in the UK in 1957 to work in obstetrics. However, she switched her interests to psychiatry and obtained her DPM in 1970 followed by her MRCPsych in 1973. Leila's earlier psychiatric jobs were at Horton Hospital, Netherne Hospital, The Maudsley Hospital, and at West Middlesex and Springfield Hospitals.

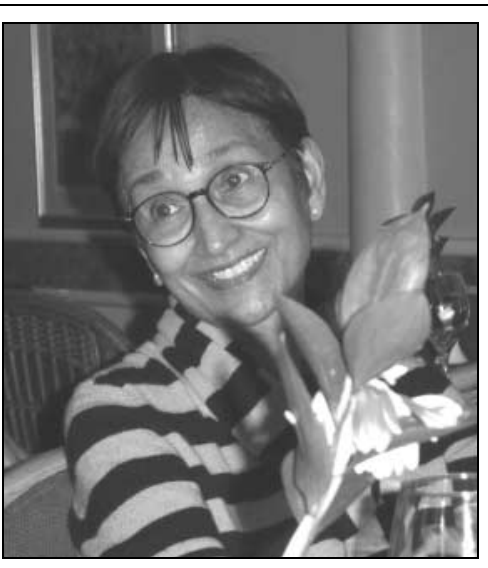

In July 1973 Leila was appointed as a Consultant Psychiatrist at St Bernard's Hospital where she remained until 1979. From 1980 onwards she became a successful private practitioner specialising in eclectic psychotherapies and remained a Visiting Consultant at The Roehampton
Priory Hospital until her retirement 2 years ago. In later years Leila took to writing and was one of the winners on two occasions of The Asham Prize for short stories by women. Her short stories were subsequently published in anthologies entitled The Catch and Harlot Red. A number of Leila's writings were also broadcast on Radio 4 in the late 1990s, including a specially commissioned story for the 50th anniversary of the Partition of India.

Leila will be sadly missed by her husband, Tony, by her three children from a previous marriage, and by a large number of colleagues and patients to whom she provided serene wisdom, a very philosophical approach and kind friendship.

Dr Saeed Islam

doi: $10.1192 / p b . b p .108 .020149$

\section{reviews}

\section{Reading about... self-help books for phobias and panic disorder}

For many people with phobias and panic disorder, reading about how to deal with their problem is a key to effective selfmanagement of their disorder. Such selfhelp is achieved alongside varying amounts of professional advice given face-to-face, by phone, book or internet. This seems to be true for disorders like diabetes, hypertension, asthma and phobia/panic. In a randomised controlled trial (RCT) carried out two decades ago, people with phobia/panic improved to a similar extent regardless of whether selfexposure guidance was given by a book, a computer program, or face-to-face by a psychiatrist (Ghosh et al, 1988). All participants in this trial attended a clinic (outpatients) and were rated by a psychiatrist four times over 6 months, which may have aided them to achieve better results. Two of the participants in the book group had bought it in a shop before being enlisted for the trial, but had not read the book until the trial began. They were then asked by the psychiatrist to do so (i.e. read the book and follow its advice) and their condition improved.

Hundreds of people with phobia/panic around the UK now receive self-help computer/internet guidance from FearFighter, a treatment recommended by NICE (National Institute for Health and Clinical Excellence, 2006), perhaps the first such recommendation by any government regulatory agency given to such a self-help device for anxiety.

Different people need varying amounts of guidance with self-help. Some manage entirely alone, like the founder of a British network of 23 self-help groups Triumph Over Phobia (TOP) did. She went to Canada by boat because she feared flying. When in Toronto, she bought Living with Fear and followed its self-exposure advice unaided. She then flew for the first time ever to return to England, and founded TOP. Triumph Over Phobia groups around the UK use Living with Fear and are led by lay people, usually ex-sufferers who overcame their phobia/panic by selfexposure. Users of FearFighter on the internet get up to an hour in all of live support by phone and/or email over 3 months. A few people doing self-help need far more support before attaining independence. The more such contact, the less apt the term self-help. Fortunately just an ounce of contact can make a ton of difference to adherence to self-help internet self-help via free, unscreened and non-moderated access tends to have huge dropout rates (Eysenbach, 2005), far higher than with systems offering brief personal contact.

Phobia/panic sufferers can find a horde of self-help pamphlets, books, audiotapes, CD-ROMs and internet systems. Reliable self-help materials can lessen stigma and empower and motivate users by showing how others have successfully overcome similar problems. Their ultimate value, however, can be hard to gauge without evidence other than their popularity, which is not always a reliable guide.

Randomised controlled trials are often regarded as a gold standard, though there are limits to what they can test. Some people benefit from reading self-help books or websites even though they would not enter a trial of the same. Randomised controlled trial attendance and rating regimes may enhance compliance and so be an unreliable guide to the benefit obtained from finding the same self-help material outside the trial. Nor is compliance a reliable guide to efficacy. For instance, relaxation without exposure has high compliance rates but low efficacy for phobia/panic.

\section{Criteria for inclusion}

While acknowledging the limits of RCTs, this paper describes self-help materials in the form of books and computer systems which were tested in such trials. For books we searched Medline and Psychinfo databases for the terms 'panic,' 'phobia,' 'self-help,' and 'bibliotherapy' in English-language publications from 1980 onwards and currently available to the public, and checked their reference lists (the ones we examined were from the UK, the USA and Australia). For computeraided self-help around the world we searched an extensive, recent review (Marks et al, 2007). We included only 